\title{
Aspectos epidemiológicos e patológicos da endocardite bacteriana em cães: 54 casos (2000-2005)
}

Epidemiological and pathological aspects of bacterial endocarditis in dogs: 54 cases (2000-2005)

\author{
Camila Spagnol, Alexandre Paulino Loretti, Eduardo Conceição \\ de Oliveira, Rosemari Teresinha de Oliveira, David Driemeier
}

\begin{abstract}
RESUMO
Endocardite Bacteriana (EB) é a inflamação séptica do endocárdio valvular e/ou mural. É uma doença de diagnóstico ante-mortem difícil devido ao quadro clínico inespecífico. A partir da consulta dos arquivos do Setor de Patologia Veterinária da Universidade Federal do Rio Grande do Sul, foi realizado um estudo retrospectivo sobre a EB canina em um período de 6 anos. De 2000 a 2005, 54 casos da doença foram diagnosticados à necropsia correspondendo a 1,72\% do total de cães necropsiados nesse período. A idade média dos animais afetados foi de 8,2 anos. Machos (32/54) foram mais afetados do que fêmeas (22/54). A doença foi observada principalmente em cães de raça (37/54) sendo Pastor Alemão (9/54) e Fila Brasileiro (8/54) as raças mais acometidas. A válvula mitral foi a mais afetada (50/54). Na maior parte dos casos (42/54), uma possível porta de entrada para as bactérias foi identificada. A origem da infeccção bacteriana usualmente eram lesões cutâneas ulceradas e inflamadas (31/42). Em parte dos casos (10/31), essas feridas de pele estavam infestadas por larvas da mosca Cochliomyia hominivorax (miíases) e apresentavam evidente contaminação bacteriana. Streptococcus beta-hemolítico foi a bactéria mais freqüentemente cultivada de amostras de sangue colhidas à necropsia (6/17). Tromboembolismo arterial, evidenciado pela presença de infartos em múltiplos órgãos e tecidos, foi observado na maioria dos cães (46/54) sendo o rim (38/46) e o baço (24/46) os órgãos mais afetados. Os dados epidemiológicos e achados patológicos apresentados nesse estudo visam auxiliar no diagnóstico clínico da EB.
\end{abstract}

Descritores: cães, cardiopatia, endocardite, tromboembolismo, septicemia, bactéria.

\section{ABSTRACT}

Bacterial Endocarditis (BE) is a septic inflammation of the valvular and/or mural endocardium. Because of nonspecific clinical signs, the antemortem diagnosis of BE in dogs is difficult. Based on a 6-year review of the records of the Section of Veterinary Pathology, Federal University of Rio Grande do Sul, Porto Alegre, RS, Brazil, this disease was studied retrospectively. From 2000 to 2005, 54 cases of EB were diagnosed in dogs at necropsy corresponding to $1.72 \%$ of the total number of dogs necropsied during this period. The median age of the affected animals was 8.2 years. Males were more frequently affected than females (32/54 versus 22/54). The disease was most commonly observed in purebred dogs (37/54), the German Shepherd Dog and the Fila Brasileiro being the two canine breeds most frequently affected. The mitral valve was the most commonly affected valve (50/54). In 42 out of 54 cases, a potential portal of entry of bacteria was identified. Ulcerated/inflamed skin lesions were the most common portal of entry for these microorganisms (31/42). In some cases (10/31), skin wounds were infested by screwworm fly (Cochliomyia hominivorax) larvae (myiases), and there was frank bacterial contamination of these lesions. Betahemolytic streptococci were the most frequent bacterium cultured from blood samples collected at necropsy (6/17). Infarcts in multiple organs and tissues (arterial tromboembolism) were present in 46 dogs (46/54), the kidney and spleen being the most frequently affected (38/46 and 24/46, respectively). The epidemiological data and pathological findings presented in this study would help local veterinary practitioners in the clinical diagnosis of EB.

Key words: dogs, cardiopathy, endocarditis, tromboembolism, septicemia, bacteria. 


\section{INTRODUÇÃO}

Endocardite bacteriana (EB) é a inflamação séptica do endocárdio valvular e/ou mural. É tida como doença incomum em cães e usualmente é fatal. Bacteremia e destruição do revestimento endotelial da válvula são alguns dos pré-requisitos para que a doença ocorra apesar de nem sempre este último fator ser necessário visto que bactérias mais patogênicas são capazes de se aderir à superfície valvular sem que haja lesão endotelial prévia [22]. Os sinais clínicos dessa enfermidade são bastante variados e inespecíficos. Isso torna a EB uma doença de diagnóstico ante-mortem difícil. Um resultado negativo da cultura bacteriana não exclui a possibilidade de EB [4], e um diagnóstico presuntivo dessa doença ainda pode ser feito com base no histórico, quadro clínico e, quando disponíveis, exames de imagem [10]. O conhecimento da epidemiologia dessa enfermidade em uma determinada região é particularmente importante nessas situações. No Brasil as endocardites bacterianas em cães já foram relatadas $[1,9,14]$.

O presente trabalho descreve os aspectos epidemiológicos e patológicos da EB em 54 cães necropsiados no Setor de Patologia Veterinária da Universidade Federal do Rio Grande do Sul durante 6 anos. Estudos retrospectivos dessa abrangência são importantes tendo-se em vista que o perfil epidemiológico é importante para auxiliar no diagnóstico da doença. Com a obtenção de um perfil epidemiológico regional da EB pretende-se auxiliar no diagnóstico clínico desta doença levando em conta as particularidades regionais.

\section{MATERIAIS E MÉTODOS}

Foram estudados 54 casos de endocardite bacteriana em cães diagnosticados à necropsia no Setor de Patologia Veterinária (SPV), Faculdade de Veterinária (FAVET), Universidade Federal do Rio Grande do Sul (UFRGS), Porto Alegre, RS, durante o período de janeiro de 2000 a dezembro de 2005. Informações relevantes tais como idade, raça, peso, sexo, sinais clínicos e achados de necropsia foram coletadas a partir da consulta das fichas de requisição e relatórios de necropsia do SPV-FAVET-UFRGS. Registros fotográficos das carcaças foram usados para a documentação do porte daqueles cães sem raça definida (SRD). Achados de necropsia incluídos neste estudo retrospectivo incluíram: (i) válvula(s) cardíaca(s) inflamada(s), (ii) ocorrência de tromboembolismo arterial (embolismo séptico) caracterizado pela presença de infartos em diferentes órgãos e tecidos, e (iii) ocorrência de insuficiência cardíaca congestiva (ICC) avaliada através da presença de achados macroscópicos e microscópicos consistentes com essa síndrome tais como edema e congestão pulmonares, fígado com congestão passiva crônica, e efusões cavitárias (ascite e hidrotórax). As válvulas cardíacas que, macroscopicamente, apresentavam lesões típicas de um processo inflamatório agudo foram examinadas microscopicamente. $\mathrm{O}$ diagnóstico definitivo de EB foi realizado através da visualização dos microorganismos em cortes histológicos e/ou hemocultura a partir de amostras colhidas à necropsia. Em 17 casos, amostras de sangue foram colhidas do coração através da punção cardíaca durante a necropsia, antes que esse órgão fosse aberto e examinado. Essas amostras de sangue foram submetidas para cultura bacteriana no Setor de Bacteriologia Veterinária e no Laboratório de Medicina Veterinária Preventiva da FAVET-UFRGS. A possível porta de entrada de bactérias foi determinada com base no histórico do animal e/ou através dos achados de necropsia.

\section{RESULTADOS}

De um total de 3136 cães necropsiados de 2000 a 2005 no SPV-FAVET-UFRGS, foram diagnosticados 54 casos de EB, correspondendo a $1,72 \%$ do total de necropsias de caninos realizadas. Cães machos foram os mais frequientemente afetados (32/54 contra 22/54), correspondendo a aproximadamente $54,3 \%$ dos casos. A idade média dos animais afetados foi de 8,2 anos. A idade dos cães acometidos variou de 2 anos a 14 anos. Os cães de raça (37/54) prevaleceram sobre os cães SRD (17/54). As raças caninas de grande porte (29/37) foram predominantes sobre as de pequeno porte (1/37), médio porte (4/37) e porte gigante (3/37). As raças caninas mais afetadas foram Pastor Alemão ( $9 /$ 54) e Fila Brasileiro (8/54). Os cães SRD (17/54) eram animais de médio porte $(9 / 17)$ ou de grande porte $(8 /$ 17). À necropsia, a válvula mitral foi a mais frequientemente acometida (51/54) (Figura 1) sendo que, na maioria dos casos, essa era a única estrutura cardíaca afetada (46/50). Em alguns casos, o mesmo animal tinha a válvula mitral e a válvula aórtica (2/54) ou a válvula mitral e a válvula tricúspide acometidas (2/54). A lesão inflamatória valvular se estendia ao endocárdio mural adjacente em três casos (3/54). Em alguns cães, apenas a válvula aórtica (2/54) ou apenas a válvula tricúspide (1/54) estavam afetadas. As válvulas cardíacas que foram examinadas histologicamente apre- 
sentavam colônias bacterianas basofílicas (Figura 2) geralmente dispostas em camadas e associadas a neutrófilos e grande quantidade de trombos de fibrina. Tromboembolismo arterial séptico foi observado na maioria dos cães com EB (46/54), ocorrendo geralmente em mais de um órgão (34/46). O órgão mais freqüentemente envolvido foi o rim (Figura 3) (38/46), seguido do baço que além de infarto apresentava-se aumentado de volume com bordos arredondados associados com hiperplasia linfóide (Figura 4) (24/46), miocárdio (10/46), encéfalo (7/46), pulmão (8/46), artérias (aorta abdominal distal/ilíacas e artéria subclávia - trombose em sela) (Figura 5) (2/46) e fígado (1/46). Achados de necropsia consistentes com ICC direita (congestão passiva crônica do fígado), esquerda (edema/congestão pulmonares) e biventricular (congestão passiva crônica do fígado e edema/congestão pulmonares) foram observados em 4 casos (4/29), 17 casos (17/29) e 8 casos (8/29), respectivamente. Nos casos em que a hemocultura foi procedida obteve-se $64,7 \%$ de resultados positivos. Streptococcus sp. beta-hemolítico foi a bactéria mais frequientemente cultivada dessas amostras (6/17), seguida de Staphylococcus sp. (2/17), Proteus sp. (2/ 17) e Acinetobacter sp. (1/17). Com relação à identificação da possível porta de entrada para os microorganismos (42/54), os cães usualmente apresentavam lesões de pele (31/42) (Figura 6) incluindo lesões cutâneas ulceradas, infectadas, inflamadas e infestadas por larvas da mosca Cochliomyia hominivorax (10/31), tumores de pele ulcerados e que exsudavam pus (6/ 31 ), soluções de continuidade devido a ferimentos perfurocortantes (9/31), fleimão (1/31), abscesso (1/31), dermatite por lambedura (1/31) (Figura 7), e lesões inflamatórias crônicas de pele de etiologia não-determinada (3/31). EB foi observada em cadelas submetidas à ovariohisterectomia não-eletiva em decorrência de piometra (7/54). Cães machos com prostatite supurativa também apresentaram EB (4/54). EB foi observada em 1 cão com doença cardíaca congênita (1/54) o qual tinha persistência do forame oval. Endocardite foi diagnosticada em 1 cão com histórico de otite bacteriana exsudativa crônica (1/54). Lesão extra-renal de uremia (gastropatia urêmica) foi observada em 1 cão com múltiplos infartos renais (1/54).

\section{DISCUSSÃO}

A prevalência da $\mathrm{EB}$ em cães não é precisamente conhecida, visto que a maioria das publicações acerca desse assunto referem-se a relatos de casos.
No presente estudo, a prevalência da EB em cães detectada à necropsia $(1,72 \%)$ está de acordo com àquela relatada em outros estudos a esse respeito [5,15,18]. Em um estudo retrospectivo sobre a prevalência de cardiopatias em cães com insuficiência cardíaca, realizado a partir da consulta dos mesmos relatórios de necropsia empregados no presente trabalho, a EB foi a terceira cardiopatia mais freqüentemente observada [17].

EB foi diagnosticada com maior freqüência em cães machos (32/54). Outros estudos também relatam uma predisposição maior dos machos a desenvolver a doença $[2,5,16]$. Alguns autores atribuem esta predisposição à ocorrência de prostatite bacteriana subaguda ou crônica nos cães machos [18,22]. No presente trabalho, prostatite foi observada em apenas 4 casos de EB. Em contrapartida, 7 fêmeas que desenvolveram a doença tinham piometra, infecção uterina que aparentemente tornou as fêmeas da população canina analisada mais predispostas à EB.

EB foi mais freqüentemente observada em cães com idade média a avançada estando de acordo com a literatura $[2,16,18]$. Segundo a literatura, a EB acomete mais freqüentemente cães de 4 a 8 anos de idade [22]. São raros os relatos de EB em cães jovens e adulto jovens, embora existam relatos da doença em filhotes e animais jovens $[18,20]$. No presente levantamento EB foi diagnosticada em um cão de 2 anos de idade que apresentava um defeito congênito no coração. Defeitos congênitos do coração, especialmente a estenose subaórtica [5,11,22] e também outros defeitos de septo $[13,16]$ têm sido relacionados aos casos de EB.

Neste estudo retrospectivo as raças caninas de porte grande e gigante foram predominantes sobre as de pequeno e médio porte indo ao encontro com o que cita a literatura. A raça Pastor Alemão, mais acometida neste estudo, é tida como uma das mais freqüentemente acometidas [16,18,22].

$\mathrm{Na}$ EB canina, as válvulas cardíacas mais comumente afetadas são as válvulas mitral e a válvula aórtica. Isto parece estar relacionado com a maior pressão e maior tensão mecânica a que essas válvulas estão sujeitas no lado esquerdo do coração, estando mais predispostas a sofrer microtraumatismos o que favorece a colonização da superfície endocárdica por bactérias [10]. No presente estudo, a válvula mitral, seguida da válvula aórtica, foram as válvulas cardíacas mais afetadas. Esses achados são consistentes com a maior parte dos estudos [2,5,18]. No entanto, alguns autores afirmam que recentemente as infecções da válvula aórtica têm 


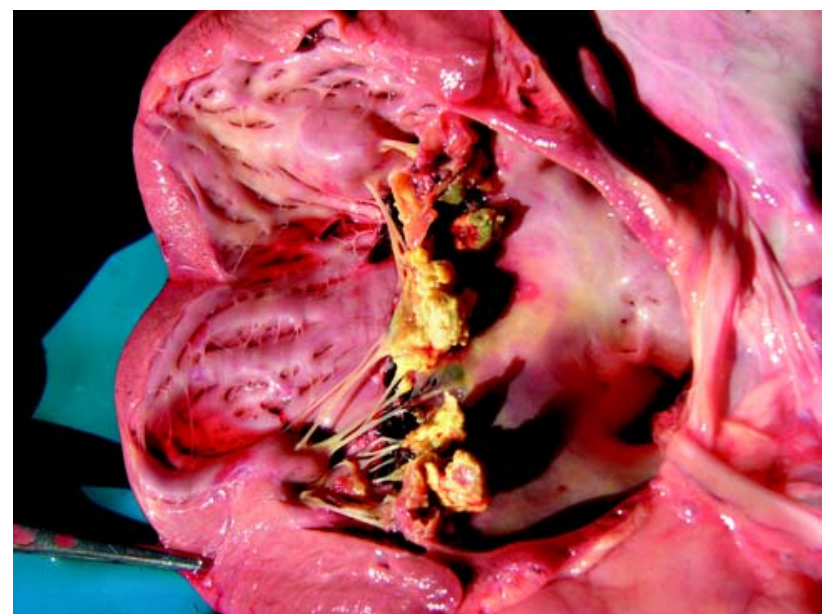

Figura 1. Endocardite valvular da válvula bicúspide caracterizada por acúmulo de material granular branco amarelado rugoso aderido ás bordas da válvula.

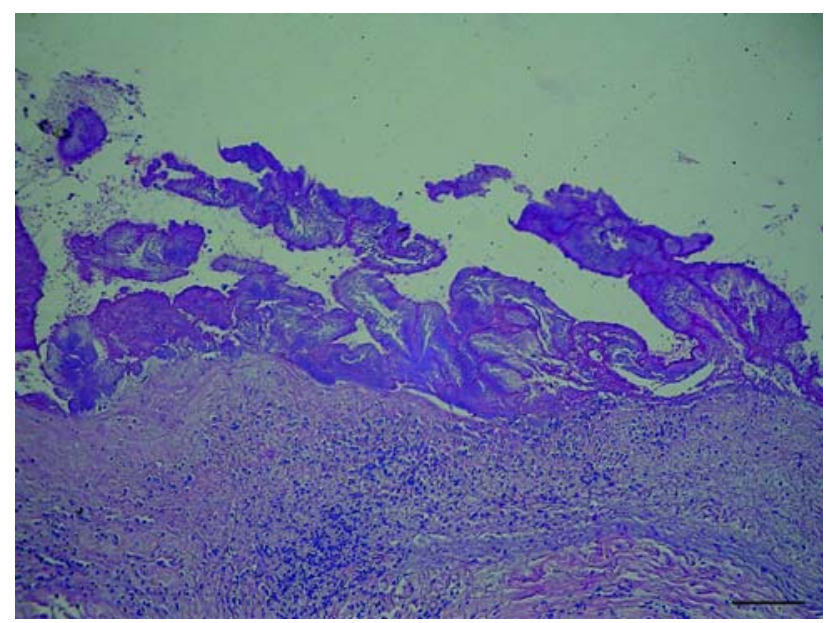

Figura 2. Achado histológico da válvula átrio ventricular esquerda apresentando acúmulo de bactérias e infiltrado neutrofílico associado com fibrina. Coloração Hematoxilina-eosina (HE). $\mathrm{Bar}=30 \mathrm{~mm}$.

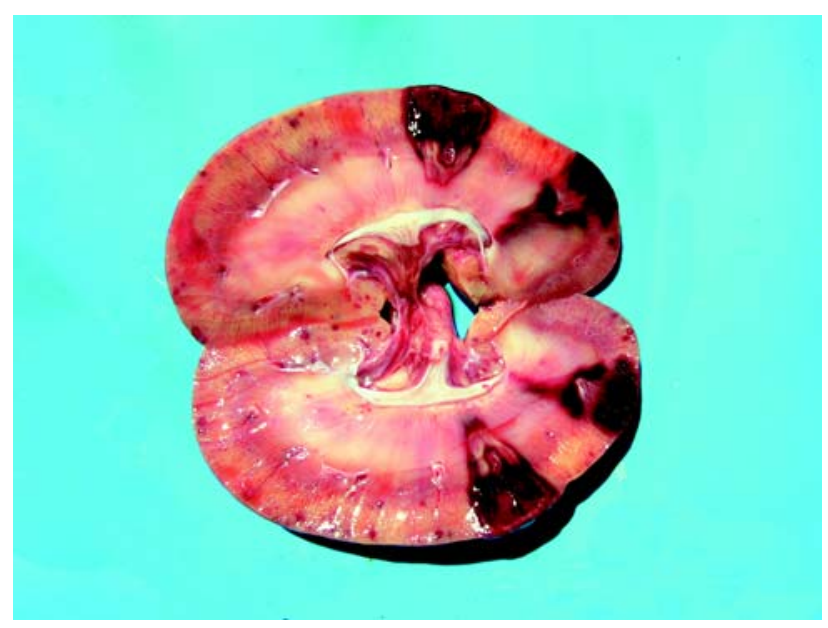

Figura 3. Tromboembolismo em conseqüência de endocardite causando múltiplos infartos em alguns em formato de cunha no rim.

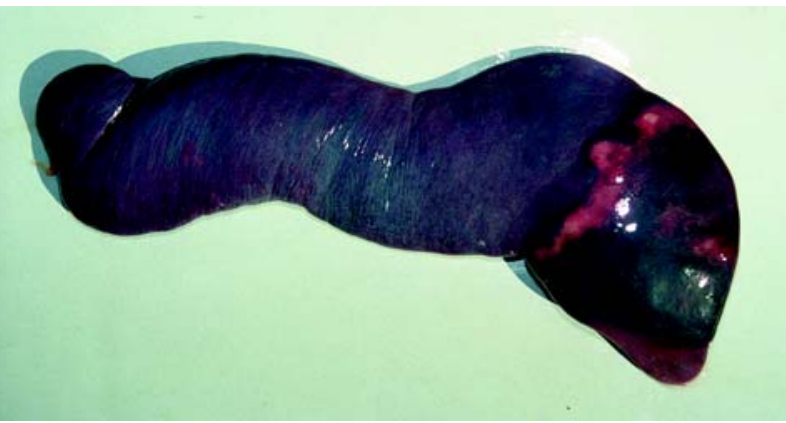

Figura 4. Tromboembolismo em conseqüência de endocardite causando infarto no baço. O baço apresenta bordos arredondados por hiperplasia linfóide. Este achado é forte indicativo de endocardite no início do procedimento de necropsia.

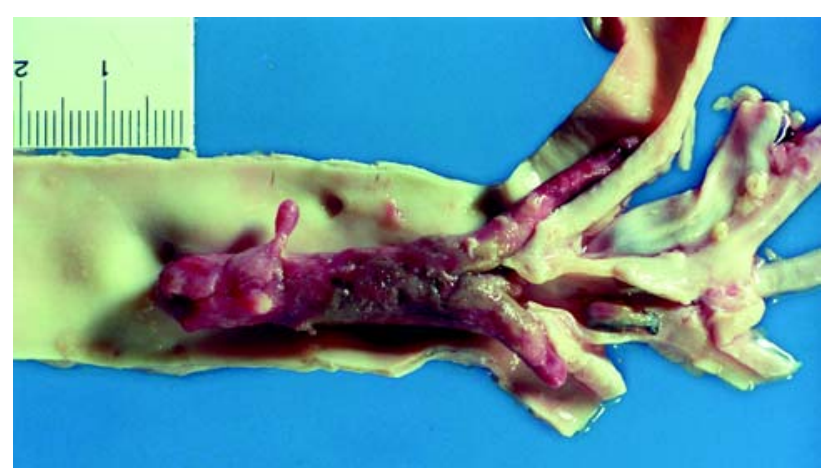

Figura 5. Trombo em sela nas artérias ilíacas como consequiência de tromboembolismo por endocardite na válvula atrioventricular esquerda.

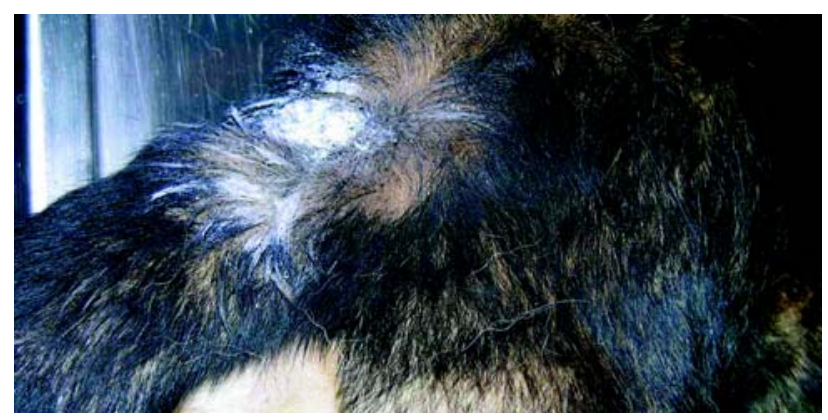

Figura 6. Canino com lesão de pele no dorso sobre a cauda. Havia miíase que foi tratada e serviu como porta de entrada de agente infeccioso que causou endocardite.

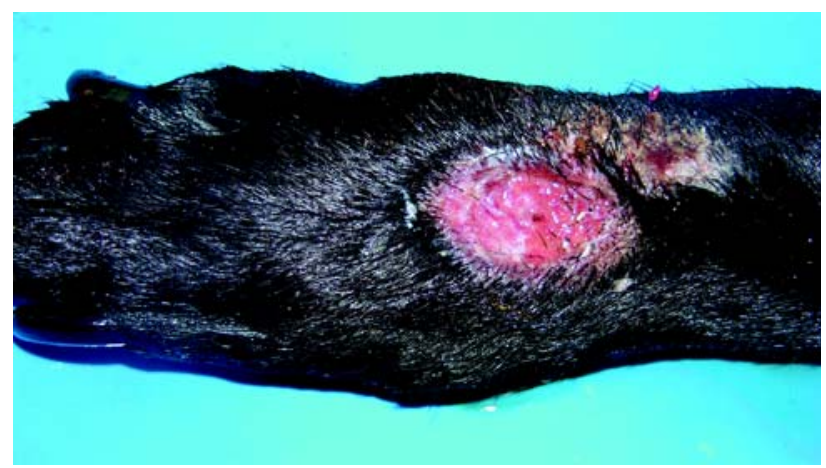

Figura 7. Dermatite por lambedura na perna de um cão com endocardite. Esta lesão foi considerada porta de entrada de agente infeccioso que causou endocardite. 
sido mais observadas do que infecções da válvula mitral [6,22].

Lesões extra-cardíacas observadas em casos de EB canina incluem infartos em múltiplos órgãos e tecidos, ocorrem secundariamente ao tromboembolismo arterial séptico. No presente trabalho, o rim, seguido do baço, foram os órgãos que mais frequientemente apresentaram infartos decorrentes desse fenômeno de tromboembolismo séptico. Achados semelhantes são descritos na literatura [5,10]. Outros órgãos afetados por tromboembolismo séptico em nossos casos - miocárdio, pulmões, encéfalo, artérias e fígado - também são mencionados nas publicações sobre o assunto [16]. ICC, caracterizada por edema e congestão pulmonares e congestão passiva crônica hepática, foi uma seqüela adicional da EB observada em nosso estudo, sendo esta relativamente comum em cães com EB segundo a literatura [11].

Em nosso trabalho, as amostras de sangue para cultura bacteriana, todas elas colhidas à necropsia, foram positivas em $64,7 \%$ dos casos. A positividade foi semelhante a outros estudos [5,16]. Falso-positivos têm sido relatados naqueles casos em que as amostras de sangue sofreram contaminação acidental, durante a colheita. Precauções durante a coleta foram tomadas a fim de evitar este tipo de contaminação. Resultados falso-negativos podem estar relacionados a diversos fatores: (i) o tratamento prévio do animal com antibióticos, (ii) a cronicidade da doença, (iii) volume e número de amostras insuficientes e (iv) microorganismos fastidiosos, principalmente em se tratando de bactérias anaeróbias [4]. Bartonella spp. também têm sido responsabilizadas por aqueles casos de $\mathrm{EB}$ em que não há crescimento bacteriano, sendo que esses microorganismos têm sido identificados através dos métodos de PCR, imunoistoquímica, microscopia eletrônica de transmissão e sorologia [12,19]. Streptococcus betahemolítico, Staphylococcus sp. e Proteus sp. foram as bactérias cultivadas em nossos casos e também já foram cultivadas em outros casos de EB relatados por outros autores [5,19,22].

A bacteremia resultante de uma inflamação extra-cardíaca é um dos pré-requisitos para a ocorrência de EB em cães [11]. Em nosso estudo, encontramos uma forte correlação entre lesões de pele ulceradas/ exsudativas e a ocorrência de EB. Muitas dessas lesões cutâneas, tidas como porta de entrada para esses microorganismos, estavam infectadas/inflamadas e infestadas por larvas de Cochliomyia hominivorax. Isso não é comentado na literatura estrangeira possivelmente pelo fato de essa mosca estar erradicada/não existir nas regiões de onde provêm vários estudos a respeito da EB em cães (América do Norte e Europa) [3]. Não foram observados no presente estudo nenhum caso de EB relacionado à procedimentos dentários, fator que foi durante muito tempo considerado predisponente ao desenvolvimento de EB [21]. Sabe-se que a bacteremia ocorre em $85 \%$ dos procedimentos dentários realizados, mas que raramente a EB se desenvolve, ocorrendo somente nos casos de bacteremia prolongada [11].

\section{CONCLUSÃO}

O presente trabalho traz dados da epidemiologia e da patologia de uma série de casos de EB em cães diagnosticados no Estado do Rio Grande do Sul, em especial na Grande Porto Alegre. Esse é um estudo retrospectivo de caráter regional e que se acredita irá auxiliar médico-veterinários de nossa área geográfica no diagnóstico clínico da EB canina. Há casos de pacientes gravemente afetados em que existe a necessidade de se estabelecer prontamente um diagnóstico presuntivo de EB, antes mesmo de se ter o resultado de exames complementares. $\mathrm{O}$ conhecimento da epidemiologia local e da patologia da EB em cães é particularmente importante nessas situações. O clínico de pequenos animais deve conhecer as particularidades dessa doença em nossa região de modo a diagnosticar correta e rapidamente tal enfermidade instituindo de imediato o tratamento mais adequado. Em nossa região, lesões de pele, especialmente miíases, são fatores de risco para a ocorrência de EB em cães. Os resultados de nosso estudo revelam que as mííases são um fator de risco para o desenvolvimento de EB em cães da nossa região de forma que esta hipótese deve ser considerada em cães com lesão de pele inflamada/ infectada quando estiver presente sopro de início recente ou sinais de infecção sistêmica tais como febre e leucocitose.

Agradecimentos. Os autores agradecem aos médicos veterinários/residentes do Hospital de Clínicas Veterinárias (HCVUFRGS) e aos médicos veterinários de clínicas veterinárias particulares pelo encaminhamento para necropsia dos cães desse estudo; à equipe do SPV-FAVET-UFRGS, especialmente às técnicas de laboratório Ângela Rosaura Belmonte de Souza e Marília de Oliveira Belmonte e pelo auxílio técnico nas necropsias e processamento histológico; às equipes do Setor de Bacteriologia Veterinária e do Laboratório de Medicina Veterinária Preventiva, FAVET-UFRGS, pelos exames bacteriológicos. 


\section{REFERÊNCIAS}

1 Abreu C.R. \& Camacho A.A. 1997. Endocardite infecciosa em cães. In: Anais do XIX Congresso Brasileiro de Clínicos Veterinários de Pequenos Animais (Curitiba, Brasil). p.47.

2 Anderson C.A. \& Dubielzig R.R. 1984. Vegetative endocarditis in dogs. Journal of the American Animal Hospital Association. 20: $149-152$.

3 Borja M.G.E. 2003. Erradicação ou manejo integrado das miíases neotropicais das Américas? Pesquisa Veterinária Brasileira. 23: $131-138$.

4 Brown V.A. 2004. Aortic valvular endocarditis in a dog. Canadian Veterinary Journal. 45: 682-684.

5 Calvert C.A. 1982. Valvular endocarditis in the dog. Journal of the American Veterinary Medical Association. 180: $1080-1084$.

6 Calvert C.A. 1998. Cardiovascular infections. In: Greene C.E. (Ed). Infectious diseases of the dog and cat. 2th edn. Philadelphia: W.B. Saunders, pp.567-579.

7 Cook L.B., Coates J.R., Dewey C.W., Gordon S., Miller, M.M. \& Bahr A. 2005. Vascular encephalopathy associated with bacterial endocarditis in four dogs. Journal of the American Animal Hospital Association. 41: 252-258.

8 Ellison G.W., King R.R. \& Calderwood-Mays M. 1988. Medical and surgical management of multiple organ infarctions secondary to bacterial endocarditis in a dog. Journal of the American Veterinary Medical Association. 193: $1289-1291$.

9 Matos M.P.C., Paula R.R., Souza M.A., Costa H.H.S., Alves R.O., Miguel M.P. \& Santos A.S. 2005. Morte súbita em cão causada por endocardite de válvula semilunar aórtica. Revista da Universidade Rural - Série Ciências da Vida. 25 (Supl 1): 155-156.

10 Miller M.W. \& Sisson D. 1999. Infectious endocarditis. In: Fox P.R. \& Sisson D., Moise N.S. (Eds). Diseases of the heart and circulation, Philadelphia: W.B Saunders, pp.567-580.

11 Miller M.W., Fox P.R. \& Saunders A.B. 2004. Pathologic and clinical features of infectious endocarditis. Journal of Veterinary Cardiology. 6: 35-43.

12 Pesavento P.A., Chomel B.B., Kasten W.R., McDonald K.A. \& Mohr F.C. 2005. Pathology of Bartonella endocarditis in six dogs. Veterinary Pathology. 42: 370-373.

13 Ramírez G.A., Monteros A.E., Rodríguez F., Weisbrode S.E., Jaber J.R. \& Herrárez P. 2003. Left ventricular outflow tract-rith atrial comunication (gerbode type defect) associated with bacterial endocarditis in a dog. Veterinary Pathology. 40: 579-582.

14 Schwartz D.S. \& Casagrande A.M. 1994. Endocardite bacteriana em cão: relato de um caso. In: XXIII Congresso Brasileiro de Medicina Veterinária (Olinda, Brasil). p.382.

15 Shouse C.L. \& Meier H. 1956. Acute vegetative endocarditis in the dog and cat. Journal of the American Veterinary Medical Association. 129: 278-283.

16 Sisson D. \& Thomas W.P. 1984. Endocarditis of the aortic valve in the dog. Journal of the American Veterinary Medical Association. 184: 570-577.

17 Spagnol C., Rozza D., Tostes S., Schwantes V. C. \& Driemeier D. 2004. Ocorrência de cardiopatias em cães com insuficiência cardíaca encaminhados ao Setor de Patologia Veterinária de janeiro de 2003 a maio de 2004. In: Resumos do XVI Salão de Iniciação Científica da UFRGS (Porto Alegre, Brasil). p.202.

18 Sykes J.E., Kittleson M.D., Chomel B.B., Macdonald K.A. \& Pesavento P.A. 2006a. Clinicopathologic findings and outcome in dogs with infective endocarditis: 71 cases (1992-2005). Journal of the American Veterinary Medical Association. 228: 1735-1747.

19 Sykes J.E., Kittleson M.D., Pesavento P.A., Byrne B.A., MacDonald K.A., Chomel B.B. 2006b. Evaluation of the relationship between causative organisms and clinical characteristics of infective endocarditis in dogs: 71 cases (1992-2005). Journal of the American Veterinary Medical Association. 228: 1723-1734.

20 Tessier-Vetzel D., Carlos C., Dandrieux J., Boulouis H.J., Pouchelon J.L. \& Chetboul, V. 2003. Spontaneous vegetative endocarditis due to Enterococcus fecalis in a Rottweiler puppy. Schweizer Archir für Tierheilkunde. 145: 432-436.

21 Tou S.P., Adin D.B. \& Castelman W.L. 2005. Mitral valve endocarditis after dental prophylaxis in a dog. Journal of Veterinary Internal Medicine. 19: 268-270.

22 Wall M., Calvert C.A. \& Greene C.E. 2002. Infective endocarditis in dogs. Compendium on Continuing Education for the Practicing Veterinarian. 24: 614-625.

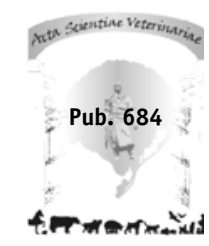

